\title{
Modelling of Long-Term Loading Tests on Reinforced Concrete Beams
}

N. Reybrouck; P. Criel; R. Caspeele; and L. Taerwe

Magnel Laboratory for Concrete Research, Department of Structural Engineering, Ghent University, Ghent, Belgium. E-mail: Robby.Caspeele@UGent.be

\begin{abstract}
During the period 1967-1985 the Magnel Laboratory for Concrete Research participated in an extensive Belgian research campaign with respect to the influence of creep and shrinkage on the long-term behaviour of reinforced and prestressed concrete beams. This research campaign, jointly conducted at several Belgian research institutes, comprised the investigation of concrete and reinforced concrete beams (phase 1), prestressed concrete beams (phase 2) and partially prestressed concrete beams (phase 3). The main aim of the research campaign was the determination of the long-term behaviour subjected to permanent loads, considering the influence of the magnitude of the loads, different reinforcement ratios and/or prestressing degrees and/or different cross-sectional shapes. These results were obtained by a joint collaboration of 4 Belgian research institutes, each focussing on a different reinforcement ratio and reinforcement arrangement. With respect to the reinforced concrete beams (phase 1), at each institute 12 beams were tested in a 4point bending configuration, namely 2 static tests at 28 days and 10 long-term tests with a duration of 2 to 4 years, considering different loading levels. In this contribution some results of the reinforced concrete beams (phase 1) will be documented and analysed, comprising the results obtained on 48 reinforced beam specimens with a length of $3.4 \mathrm{~m}$ (span of $2.8 \mathrm{~m}$ ) and cross-section of $0.28 \mathrm{~m} \mathrm{x} 0.15$ $\mathrm{m}$. A cross-sectional calculation tool developed at our department - incorporating the current creep and shrinkage models in standards and guidelines - will be employed in order to investigate the accuracy of the available models with respect to their ability to predict the structural behaviour of the documented reinforced concrete beams.
\end{abstract}

\section{INTRODUCTION}

During the period 1967-1985, in Belgium a large set of concrete beams was tested with respect to the influence of creep and shrinkage on the long-term behaviour of reinforced and prestressed concrete beams. Several research institutes participated in this Belgian research campaign, including: Ghent University (UGent), the Vrije Universiteit Brussel (VUB), l'Université Libre de Bruxelles (ULB), KU Leuven, l'Université Catholique de Louvain (UCL) and l'Université de Liège (ULG). The main aim of this large research campaign was the determination of the long-term behaviour of concrete beams under permanent loads, considering the influence of the magnitude of the permanent loads (as a percentage of the ultimate load), different 
reinforcement ratios and/or prestressing degrees and/or different cross-sectional shapes (Lambotte, Van Nieuwenburg, \& Taerwe, 1988).

In this contribution some results of the reinforced concrete beams (phase 1) will be documented and analysed, comprising the results obtained on 48 reinforced beam specimens. These results were obtained by a joint collaboration of 4 Belgian research institutes. Each of these research institutes focussed on a different reinforcement ratio and reinforcement arrangement. The cross-sectional shape was the same for each research institute. One purchase was made for the reinforcement steel and the materials for the concrete to minimize the variation of the material characteristics. Afterwards the materials were distributed between the participating research institutes.

At each institute 12 beams were tested, namely 2 static tests at 28 days and 10 long-term tests. More specifically, the evolution of the deflections due to creep and shrinkage at mid-span, the deformations of the concrete cross-section and the evolution of the cracks were closely monitored during the period of the experiment. The ultimate load was experimentally obtained from the 2 static tests. The reinforcement ratio and arrangement for the different cross-section were chosen so that the beam specimens would fail due to yielding of the reinforcement steel (crosssections I, II and IV) or by (theoretically) simultaneous yielding of the steel and crushing of the concrete (cross-section III).

Due to the high load levels considered in this first phase of the research campaign the stresses in the concrete will exceed $40 \%$ of the concrete strength. Such high stresses relative to the concrete strength have as a consequence that the timedependent behaviour of concrete cannot be regarded as linear with the concrete stress. Hence adjustments of the creep coefficient will be required.

\section{TEST PROCEDURE}

The total length of each beam is $3.4 \mathrm{~m}$. Each beam is placed on two supports $2.8 \mathrm{~m}$ apart. One of these two supports allows free horizontal movement so that the creep and shrinkage deformations are not restricted by the supports. The beams are loaded by means of a 4-point bending test in which the point loads are placed at respectively one third and two thirds of the span. For the long-term measurements the beams are placed in pairs in a steel frame in such manner that they do not need to be supported by a reaction floor (except for the unloaded beams). To determine the ultimate loading, a traditional test setup was used. Additionally, for each beam type, a beam was placed on its supports without loading to measure the effects of shrinkage. The test setup for both the long-term test as for the static test is illustrated in Figure 1. 


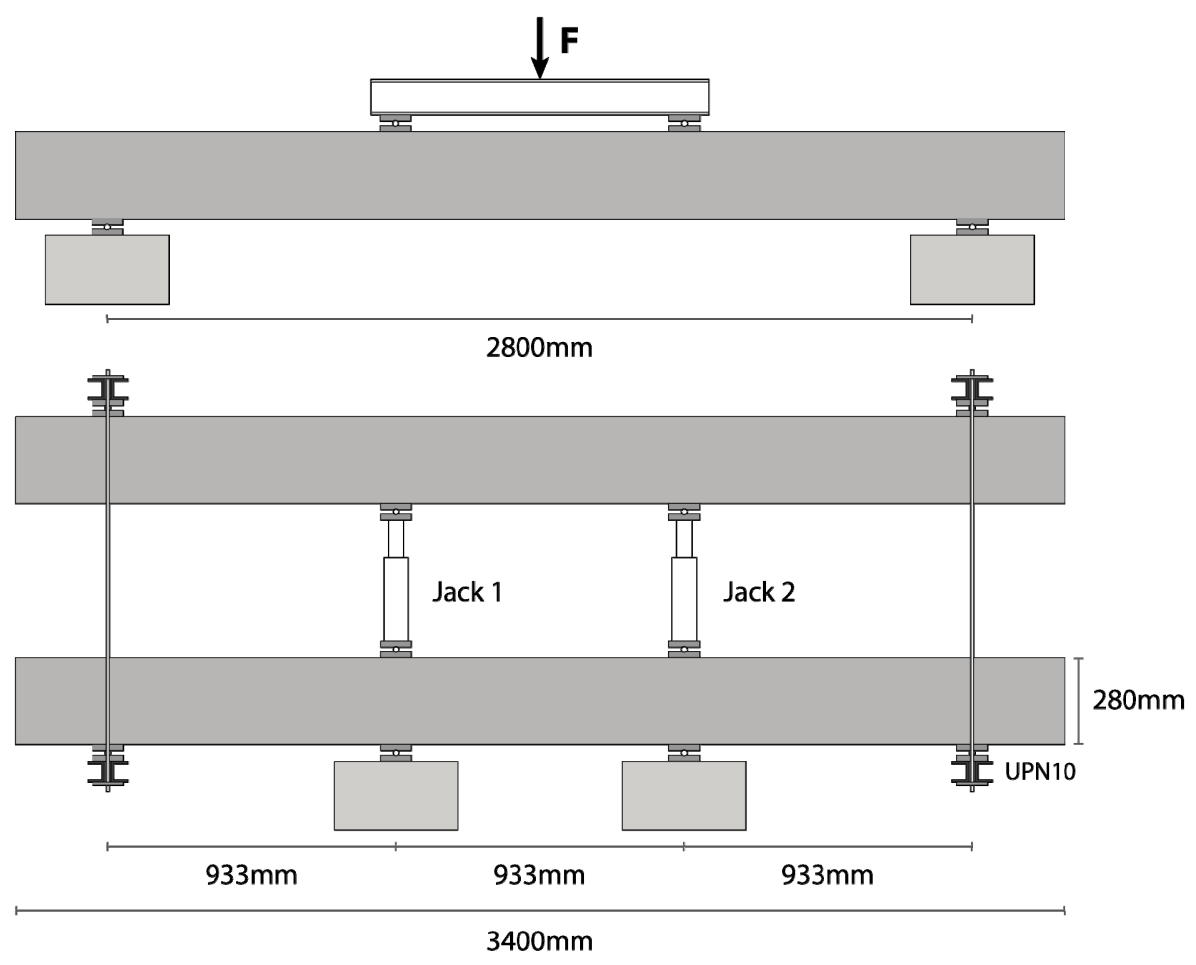

Figure 1 Test setup for the (a) static and (b) long-term tests

Four reinforcement schemes were considered in this experimental programme (part of a the larger research campaign). The first three types consist only of tensile reinforcement, while the last scheme also has some compressive reinforcement steel present. All reinforcement bars have a diameter of $14 \mathrm{~mm}$ and have a characteristic yield strength of 400MPa. These reinforcement schemes are given in Figure 2.

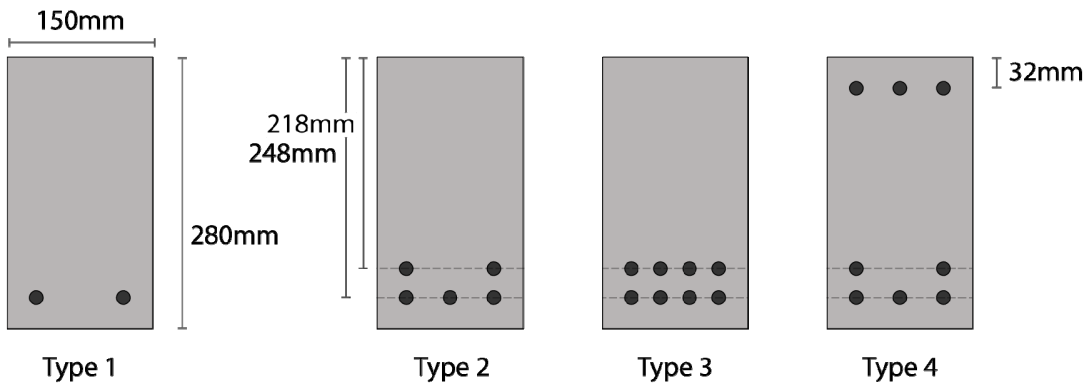

Figure 2 Dimensions and reinforcement schemes for the different beam types

\section{Static tests}

The beams are loaded in four equal steps up to the theoretical service load. Subsequently the load is completely removed. This procedure is then repeated to reach the service load again. Subsequently the load is increased by steps of $5 \%$ of the theoretical ultimate load until failure occurs.

The following ultimate moments $\mathrm{M}_{\mathrm{u}, 0}$ were obtained from the static loading tests for each reinforcement arrangement respectively: (I) $29.9 \mathrm{kNm}$, (II) $65.1 \mathrm{kNm}$, 
(III) $97.8 \mathrm{kNm}$ and (IV) $72.8 \mathrm{kNm}$. Reinforcement arrangement III exhibits the highest ultimate load.

\section{Long-term tests}

The long-term tests start when the concrete age is equal to 28 days. As illustrated above, each testing frame contains two beams, which are mirrored. In a first loading phase, the beams were loaded in the same manner as described for the static tests. After complete unloading the load is increased to the theoretical service load and subsequently increased in steps of $5 \%$ of the theoretical ultimate load up to $40-60 \%$, $70 \%, 80 \%$ and $90 \%$ of the observed ultimate load obtained from the static tests. Two additional beams for each reinforcement arrangement remained unloaded in order to measure the shrinkage behaviour of the beams.

Accumulation vessels are used to sustain the pressure in the hydraulic jacks, hence keeping the load constant. All long-term tests were executed under constant environmental conditions of $20^{\circ} \pm 1^{\circ} \mathrm{C}$ and $60 \% \pm 5 \%$ relative humidity.

\section{MEASUREMENTS}

A summary of the instantaneous deflection measurements and the time-dependent deflections for 30 beams (each result given is the average of the measurements of the two beams in the loading frame) is given in Table 1.

Table 1 Summary of the time-dependent deflections for the different reinforcement schemes and load levels

\begin{tabular}{cccc}
$\begin{array}{l}\text { Type 1 } \\
\boldsymbol{M}_{\boldsymbol{s}} / \boldsymbol{M}_{\boldsymbol{u}, \mathbf{0}}\end{array}$ & $\boldsymbol{a}_{\mathbf{0}}[\mathrm{mm}]$ & $\boldsymbol{a}_{\boldsymbol{t}}[\mathrm{mm}]$ & $\begin{array}{c}\text { Duration } \\
\text { [days] }\end{array}$ \\
\hline 0.58 & - & - & 1450 \\
0.72 & 6,02 & 10,29 & 1638 \\
0.81 & 7,39 & 11,98 & 1372 \\
0.91 & 8,94 & 15,02 & 1342 \\
\hline
\end{tabular}

\begin{tabular}{cccc}
$\begin{array}{c}\text { Type } 2 \\
\boldsymbol{M}_{\boldsymbol{s}} / \boldsymbol{M}_{\boldsymbol{u}, \mathbf{0}}\end{array}$ & $\boldsymbol{a}_{\mathbf{0}}$ [mm] & $\boldsymbol{a}_{\boldsymbol{t}}[\mathrm{mm}]$ & $\begin{array}{c}\text { Duration } \\
\text { [days] }\end{array}$ \\
\hline 0.52 & 7,27 & 13,49 & 1426 \\
0.59 & 7,69 & 14,10 & 1569 \\
0.70 & 9,36 & 17,56 & 1499 \\
0.80 & 10,72 & 20,24 & 1513 \\
0.90 & 13,10 & 24,23 & 1519 \\
\hline
\end{tabular}

\begin{tabular}{cccc}
$\begin{array}{l}\text { Type 3 } \\
\boldsymbol{M}_{\boldsymbol{s}} / \boldsymbol{M}_{\boldsymbol{u}, \mathbf{0}}\end{array}$ & $\boldsymbol{a}_{\mathbf{0}}$ [mm] & $\boldsymbol{a}_{\boldsymbol{t}}$ [mm] & $\begin{array}{c}\text { Duration } \\
\text { [days] }\end{array}$ \\
\hline 0.43 & 7,08 & 14,51 & 1600 \\
0.67 & 10,58 & 23,88 & 1600 \\
0.77 & 13,84 & 28,74 & 1600 \\
\hline
\end{tabular}

\begin{tabular}{cccc}
$\begin{array}{c}\text { Type } \mathbf{4} \\
\boldsymbol{M}_{\boldsymbol{s}} / \boldsymbol{M}_{\boldsymbol{u}, \mathbf{0}}\end{array}$ & $\boldsymbol{a}_{\mathbf{0}}[\mathrm{mm}]$ & $\boldsymbol{a}_{\boldsymbol{t}}[\mathrm{mm}]$ & $\begin{array}{c}\text { Duration } \\
\text { [days] }\end{array}$ \\
\hline 0.52 & 5,98 & 10,52 & 800 \\
0.70 & 8,80 & 13,90 & 800 \\
0.80 & 11,16 & 16,96 & 1000 \\
0.90 & 12,85 & 19,28 & 1000 \\
\hline
\end{tabular}

$a_{0}$ indicates the instantaneous deflection due to the application of the load at 28 days, while $a_{t}$ is the deflection after the duration of each test specifically.

Measurement results at 28 days for the concrete strength and modulus of elasticity for each beam type are available. The average concrete strength for each type is: (I) $35.5 \mathrm{MPa}$, (II) $31.5 \mathrm{MPa}$, (III) $36.3 \mathrm{MPa}$ and (IV) $33.9 \mathrm{MPa}$. The secant 
moduli of elasticity for the beam types are: (I) $35.5 \mathrm{GPa}$, (II) $31.0 \mathrm{GPa}$, (III) $27.8 \mathrm{GPa}$ and (IV) $29.2 \mathrm{GPa}$.

\section{CROSS-SECTIONAL CALCULATION PROCEDRUE}

The deflection of the beam as function of time is calculated based on a cross-sectional approach using the Age Adjusted Effective Modulus Method (Bažant, 1972; Ghali \& Favre, 2011; Gilbert \& Ranzi, 2010). A general procedure was used as briefly described in the next paragraph in order to determine the deflection while taking into account the effects of creep and shrinkage and the effect of restraining by the reinforcement.

Concrete subjected to a sustained load deforms gradually as a result of creep and free shrinkage. However, these deformations of the concrete are partly restrained by the reinforcement. In order to asses this behaviour, the free shrinkage and creep are restrained by an artificial restraining stress. The resultant forces $(\Delta N$ and $\Delta M)$ are calculated by integrating the artificial restraint stress of the area of the cross-section. The opposite force $-\Delta N$ and $-\Delta M$ is introduced on the cross-section using transformed sectional properties to remove the restraint, resulting in additional stress, strain and curvature of the cross section.

The instantaneous curvature $\kappa_{0}$ and the strain $\varepsilon_{0}$ caused by a moment $M$ can be determined by:

$$
\left[\begin{array}{c}
\varepsilon_{0} \\
\kappa_{0}
\end{array}\right]=\left(\frac{1}{E A \cdot E I-E S^{2}}\right)\left[\begin{array}{c}
-E S \\
E A
\end{array}\right] M
$$

in which $E A, E S$ and $E I$ are respectively the area, the first moment of area and the second moment of area of the transformed cross-section multiplied with a reference modulus of elasticity of concrete, which is equal to the modulus of elasticity measured at an age of 28 days. These cross-section properties are calculated relative to a random but fixed reference fibre. The centroid of the compressive zone is chosen for this reference fibre. The transformed cracked cross-section properties are given by:

$$
\begin{gathered}
E A=E_{c}\left(t_{0}\right) W x_{c r}+E_{s} \sum_{i}^{n} A_{s, i} \\
E S=E_{s} \sum_{i}^{n}\left[A_{s, i} \cdot\left(\frac{x_{c r}}{2}-y_{s, i}\right)\right] \\
E I=E_{c}\left(t_{0}\right) \frac{W \cdot x_{c r}{ }^{3}}{12}+E_{s} \sum_{i}^{n}\left[A_{s, i} \cdot\left(\frac{x_{c r}}{2}-y_{s, i}\right)^{2}\right]
\end{gathered}
$$

with $E_{c}\left(t_{0}\right)$ the modulus of elasticity at time of loading $t_{0}, E_{s}$ the modulus of elasticity of steel, $x_{c r}$ the height of the compressive zone, $y_{s}$ the location of the reinforcement relative to the reference fibre, $W$ the width of the beam, $A_{s}$ and $A_{c}$ the steel area of steel of steel and concrete, respectively. The total steel area is the sum of the area of each individual reinforcement bar $A_{s, i}$. 
Based on the principle of superposition, the total curvature can be written as the sum of the instantaneous curvature and an additional curvature due to concrete creep and shrinkage (Khor et al., 2001).

The additional curvature caused by creep and shrinkage effects is given as:

$$
\kappa_{t}=\frac{-E S \cdot N_{c r, s h}+E A \cdot M_{c r}}{E A \cdot E I-E S^{2}}
$$

in which the restraining forces due to the shrinkage and creep effects are defined by:

$$
\begin{gathered}
N_{c r, s h}=\bar{E}_{\mathrm{c}}\left(t_{e}, t_{0}\right) A_{c 0}\left[\varepsilon_{O} \phi_{k}\left(t_{e}, t_{0}\right)+\varepsilon_{s h}\left(t_{e}, t_{0}\right)\right] \\
M_{c r}=\bar{E}_{\mathrm{c}}\left(t_{e}, t_{0}\right) I_{c o} \phi_{k}\left(t_{e}, t_{0}\right) \kappa_{O}
\end{gathered}
$$

$t_{e}$ is the duration of the long-term test expressed in days and $\bar{E}_{\mathrm{c}}\left(t_{e}, t_{0}\right)$ is the age adjusted effective modulus as defined by:

$$
\bar{E}_{\mathrm{c}}\left(t_{e}, t_{0}\right)=\frac{E_{c}\left(t_{0}\right)}{1+\chi \phi\left(t_{e}, t_{0}\right)}
$$

$\chi$ is the ageing coefficient and $\phi\left(t_{e}, t_{0}\right)$ is the creep coefficient. A constant value of 0.8 is assumed for the ageing coefficient (Bažant, 1972, 1988). In the following calculations the creep coefficient given in Eurocode 2 is used (CEN, 2004).

For concrete stresses exceeding $0.45 f_{c k}$, the non-linear behaviour of creep is defined as (CEN, 2004):

$$
\phi_{k}\left(t, t_{0}\right)=\phi\left(t, t_{0}\right) \exp \left(1.5\left(k_{\sigma}-0.45\right)\right)
$$

in which $k_{\sigma}$ is the ratio between the concrete strength and the average concrete stress at the time of loading.

If the curvature is known, the deflection of the beam can easily be found by integration. The deflection in function of the curvature at mid-span and the position of the point loads is given by:

$$
\delta_{M}=\left(\frac{3 L^{2}-4 a^{2}}{24 E I}\right) \kappa
$$

$a$ is the distance between the point-loads and the supports, $L$ is the length of the beam. 


\section{RESULTS}

The cross-sectional approach described above is applied on the described beam tests.

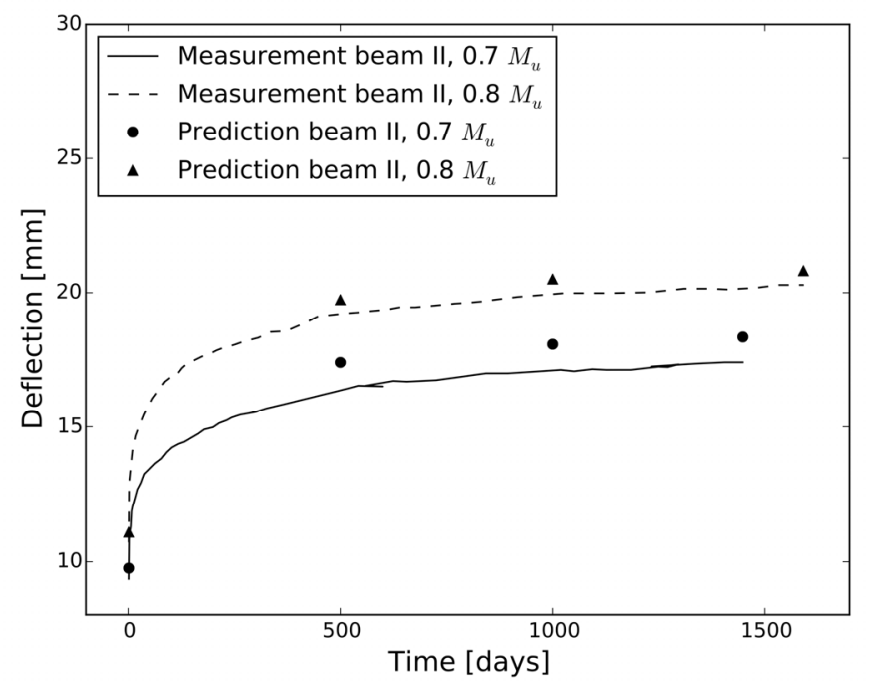

Figure 3 Measurements of the type II beams loaded with $0.7 M_{u}$ and $0.8 M_{u}$ and the predicted results.

Both the measurements and the predicted values for the beams of type II, respectively loaded with $70 \%$ and $80 \%$ of the ultimate moment are given in Figure 4.

An overview of all predicted values versus the measurements is given in Figure 4. The black-filled markers indicate the instantaneous deflections, while the white-filled markers indicate the deflection after the duration of each experiment individually. 


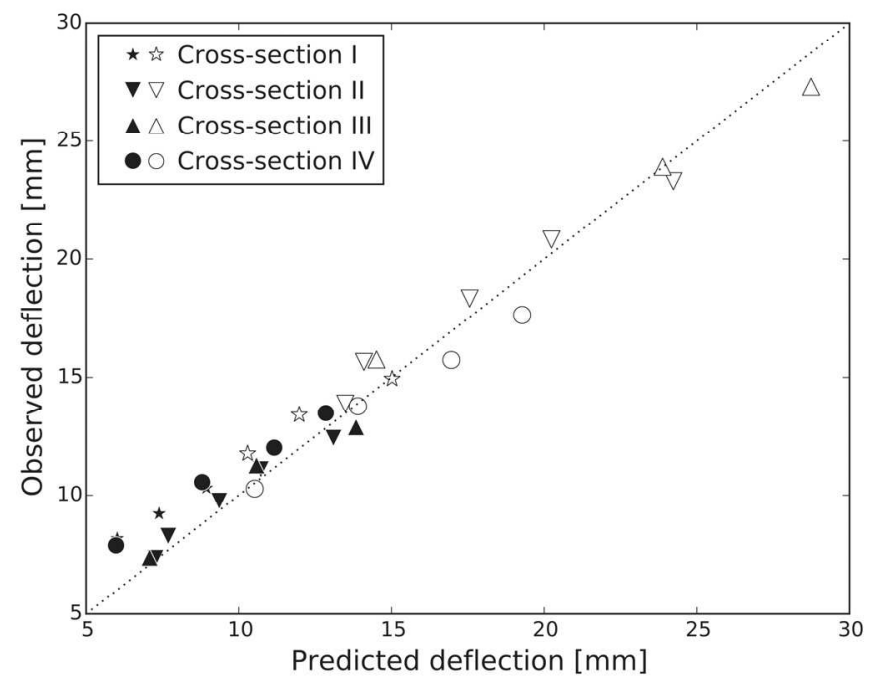

Figure 4 Measured and observed deflection after application of the loads (blackfilled markers) and after the duration of the tests (white-filled markers)

The average ratio between the predicted and the observed instantaneous deflection is equal to 0.92 with a standard deviation of 0.10 . The average ratio between the predicted and observed deflection after the duration of the tests is equal to 0.99 with a standard deviation of 0.07 .

A slight underestimation of the predicted results is observed in both the instantaneous deflection and the deflection after creep. It is noted that this approach should be regarded as an approximation. First, a constant value for the ageing coefficient is assumed. Second, this approach makes no attempt to capture the shape of the creep curve under high stresses. It merely represents a simplification of the non-linear creep-stress relation since the general creep coefficient is just increased by a factor.

\section{CONCLUSIONS}

Phase 1 of an extensive Belgian research campaign with respect to the influence of creep and shrinkage on the long-term behaviour of reinforced, partial prestressed and prestressed concrete beams is presented. 48 beams were manufactured and tested divided over several Belgian research institutes, each focussing on a particular subset of the experimental programme. From the experiments and the analysis following conclusions can be drawn.

- The interpolation factor for tension stiffening $\zeta$ is larger than 0.97 for all the considered beams. As a consequence the effect of tension stiffening can be neglected due to the overall cracking behaviour. Hence, only a small portion of the beam is uncracked near the supports and their effect seems negligible with respect to the predicted deflections. 
- The Age Adjusted Effective Modulus Method is a suitable method for fast calculations.

- High concrete stresses can be accounted for using an exponential correction factor for non-linear creep as defined in EN1992-1-1. This correction factor is reduced to only the part of the cross-section where concrete stresses exceed $0.45 f_{c k}$.

\section{REFERENCES}

Bažant, Z. P. (1972). Prediction of Concrete Creep Effects Using Age-Adjusted Effective Modulus Method. Journal Proceedings, 69(4). doi: 10.14359/11265 Bažant, Z. P. (1988). Mathematical Modeling of Creep and Shrinkage of Concrete. New York: John Wiley \& Sons.

CEN. (2004). EN 1992-1-1: Eurocode 2: Design of concrete structures - Part 1-1: General rules and rules for buildings. Brussels.

Ghali, A., \& Favre, R. (2011). Concrete Structures: Stresses and Deformations: Analysis and Design for Sustainability, Fourth Edition: Taylor \& Francis.

Gilbert, R. I., \& Ranzi, G. (2010). Time-Dependent Behaviour of Concrete Structures: Taylor \& Francis.

Lambotte, H., Van Nieuwenburg, D., \& Taerwe, L. (1988). Cracking and Crack Widths of Partially Prestressed Concrete Members. Paper presented at the European Conference on Cracking of Concrete and Durability of Constructions, AFREM-CCE, Saint-Remy-Les-Cheveuse. 